\title{
GENERAL CALCULATION OF WINDING FACTOR FOR MULTI-PHASE/-LAYER ELECTRICAL MACHINES IRRESPECTIVE OF POLES NUMBER
}

\author{
Daoud Ouamara $^{a, b, *}$, FrÉdéric Dubas $^{a}$, Sid Ali Randi ${ }^{c}$, \\ Mohamed Nadjib Benallal ${ }^{b}$, Christophe Espanet $^{d}$ \\ ${ }^{a}$ Univ. Bourgogne Franche-Comté, Département ENERGIE, FEMTO-ST, CNRS, F90000 Belfort, France \\ ${ }^{b}$ Khemis Miliana University, Laboratory of Energy 8 Smart System LESI, Ain Defla, Algeria \\ ${ }^{c}$ Renault S.A., 78280 Guyancourt, France \\ ${ }^{d}$ Univ. Bourgogne Franche-Comté, 90000 Belfort, France \\ * corresponding author: daoud.ouamara@gmail.com
}

\begin{abstract}
In this paper, a method to calculate the winding factor by only considering stator parameters without the rotor ones is developed. This is interesting because it allows the separation of the stator and rotor design, unlike the existing methods in the literature. A general method based on the matrix representation of a winding is presented. This approach requires the knowledge of four parameters : i) slots number, ii) phases number, iii) layers number, and iv) single-phase spatial distribution. A new feature of the multi-layer windings is introduced, it is called false-zero windings, which is divided into two categories: i) $\alpha$-windings (i.e., odd false-zero windings), and ii) $\beta$-windings (i.e., even false-zero windings). The windings having no false-zero are categorized as $\gamma$-windings. The calculations are applied for single and multi-phase/-layer windings. The results of the comparison are satisfactory. The code used for the calculation is given in Appendix.
\end{abstract}

KEYWORDS: False-zero windings, matrix representation, multi-phase/-layer, winding factor.

\section{INTRODUCTION}

\subsection{Context}

Rotational force generating devices, such as motors, electric generators and sirens, are generally composed of two components called stator and rotor, in which a winding is inserted in one or both sets. The winding is one of the most important and critical elements in such machines. Several types of windings are developed and studied to achieve the desired performances for a given application, viz.: full-/short-/long-pitch winding, concentrated around teeth winding, ..., distributed winding, etc. Recently, Ouamara et al. (2018) [1] published an overview on the winding design and developed a research tool called ANFRACTUS Tool 1.0 allowing an automatic generation of all windings in multi-phase/-layer electrical machines by using the matrix representation.

The way the coils are distributed in the stator and/or rotor slots directly affects the winding factor of each spatial harmonic and, therefore, the electromagnetic performances of electrical machines (e.g., the self-/mutual-inductances, the back electromotive force, the electromagnetic torque, unbalanced magnetic forces, ...., the permanent-magnet eddy-current losses, the efficiency). The winding factor is then defined as the ratio of flux linked by an actual winding to flux that would have been linked by a full-pitch winding with the same number of turns [2]. The wind- ing is spatially distributed in the stator and/or rotor slots, whereby the flux penetrating the coils does not pass through all the coils simultaneously but with a certain phase shift. Consequently, the back electromotive force of the winding is not directly calculated with the number of turns, but the winding factor corresponding to each harmonic must be taken into account [3]. In order to compensate the low torque of an electrical machine having a low winding factor, it is necessary to supply it with a higher current or using more turns [4].

In the literature, different methods for calculating the winding factor have been proposed. By using the Star of slots method [5], the computation is performed for fractional-slot three phase synchronous machines with single and two layers [6]-[8] and for multi-phase machines 9 . The electromotive force phasor vector is used to calculate the winding factor of concentrated multi-layer windings as explained in [10]. Using analytical expressions, the winding factor can be calculated from the distribution factor and the pitch factor [11]-13. In [14, the equations for a specific winding layout have been applied for multi-phase permanent-magnet synchronous machines having all teeth wound concentrated windings.

\subsection{Objective of this Paper}

The purpose of this work is to establish a general and simple method for calculating the winding factor 
regardless of the number of slots, phases and layers. Only, the knowledge of the spatial distribution of single-phase coils in slots is sufficient. To the best of the author's knowledge, the fact that the number of pole pairs is not taken into account for calculating the winding factor is not reported in the literature. This allows to design the windings without constraints on the number of pole pairs.

The terms used to describe the method and notion of false-zero windings are described in Section 2 , where the difference between $\alpha$-windings and $\beta$-windings are explained. In Section 3, $\gamma$-windings are introduced, and also, the equations used to calculate the winding factor for each case are explained in detail with some examples. Section 4 deals with the multi-layer windings in order to validate the calculations outlined in this article. Some specific windings in [15-[17] have been used and compared with the results obtained by the developed method. Finally, the algorithm written in Matlab allowing the calculation of the winding factor is given in Appendix.

\section{Notions of the Method}

\subsection{Matrix Representation}

Instead of using the usual diagrams, the stator and/or rotor windings distribution can be represented by a connection matrix $\left[M_{w}\right]$ linking the $m$-phases (i.e., the matrix rows) to the stator and/or rotor slots (i.e., the matrix columns). In [18, this concept was used to design fractional-slot windings. A table was used for the coil arrangement in [19]. In order to represent multi-layer windings, [1] has subdivised the number of columns of $\left[M_{w}\right]$ by the number of layers. This new connecting matrix $\left[C_{w}\right]$ (of dimensions $m \times Q_{s} \cdot L_{y}$ whose $m, Q_{s}$ and $L_{y}$ are respectively the number of phases, slots and layers) is defined by:

$\left[C_{w}\right]=\left[\begin{array}{cccc}1 & 2 & \cdots & Q_{s} \\ {\left[C_{w_{k}}^{1,1}\right]} & {\left[C_{w_{k}}^{1,2}\right]} & \cdots & {\left[C_{w_{k}}^{1, Q_{s}}\right]} \\ {\left[C_{w_{k}}^{2,1}\right]} & {\left[C_{w_{k}}^{2,2}\right]} & \cdots & {\left[C_{w_{k}}^{2, Q_{s}}\right]} \\ \vdots & \vdots & & \vdots \\ \vdots & \vdots & & \vdots \\ {\left[C_{w_{k}}^{m, 1}\right]} & {\left[C_{w_{k}}^{m, 2}\right]} & \cdots & {\left[C_{w_{k}}^{m, Q_{s}}\right]}\end{array}\right] \begin{gathered}1 \\ \vdots \\ m\end{gathered}$

The elements $\left[C_{w_{k}}^{i, u}\right]$ (where $i=1, \ldots, m ; u=$ $1, \ldots, Q_{s}$ and $\left.k=1, \ldots, L_{y}\right)$ are equal to:

- $\mathbf{0}$ if no conductor of phase $i$ in the $u^{\text {th }}$ slots and $k^{\text {th }}$ layers;

- $+\mathbf{1}$ if forward conductor of phase $i$ in the $u^{\text {th }}$ slots and $k^{t h}$ layers;

- $-\mathbf{1}$ if return conductor of phase $i$ in the $u^{\text {th }}$ slots and $k^{\text {th }}$ layers.

The false-zero windings are visible thanks to the use of $\left[C_{w}\right]$ (see Section 2.2). Nevertheless, the windings' distribution will be represented by:

$$
\left[D_{w}\right]=\frac{1}{L_{y}} \times\left[C_{w}\right]
$$

For example, Figure 1 represents $\left[D_{w}\right]$ for a stator of an electrical machine with $Q_{s}=6, m=3$ and $L_{y}=2$.

Throughout this study, only the first row will be considered (i.e., the first phase) of $\left[D_{w}\right]$, viz., $\left[V_{w}\right]=$ $\left[D_{w_{k}}^{1, u}\right]$ (of dimension $\left.1 \times Q_{s} \cdot L_{y}\right)$. However, one of the other phases can also be chosen since the phases are balanced. For the last example, $\left[V_{w}\right]$ is given by:

$$
\left[V_{w}\right]=\frac{1}{2}\left[\begin{array}{ccccccc}
0 & 1 & 0 & 0 & -1 & 0 & \ldots \\
\ldots & 0 & -1 & 0 & 0 & 1 & 0
\end{array}\right]
$$

The vector $\left[V_{w}\right]$ may be separated into $L_{y}$ subvectors $\left[V_{w}^{\prime}\right]$ (of dimension $1 \times Q_{s}$ ) according to:

$$
\left.\left[V_{w}^{\prime}\right]_{k}=\left[V_{w}\right]\left\{k+(u-1) \cdot L_{y}\right)\right\} \quad \forall k
$$

For the last example, $\left[V_{w}^{\prime}\right]$ of each layer is:

$$
\begin{array}{r}
{\left[V_{w}^{\prime}\right]_{1}=\left[V_{w}\right]\{1,3,5,7,9,11\}} \\
{\left[V_{w}^{\prime}\right]_{2}=\left[V_{w}\right]\{2,4,6,8,10,12\}}
\end{array}
$$

$$
\begin{aligned}
{\left[V_{w}^{\prime}\right]_{1} } & =\frac{1}{2}\left[\begin{array}{llllll}
0 & 0 & -1 & 0 & 0 & 1
\end{array}\right] \\
{\left[V_{w}^{\prime}\right]_{2} } & =\frac{1}{2}\left[\begin{array}{llllll}
1 & 0 & 0 & -1 & 0 & 0
\end{array}\right]
\end{aligned}
$$

Figure 2 shows the sub-vectors $\left[V_{w}^{\prime}\right]_{1}$ and $\left[V_{w}^{\prime}\right]_{2}$ extracted from the winding in Figure 1 .

\subsection{Notion of FAlse-Zero}

\subsubsection{DEFINITION}

Figure 3 shows an example of a one phase distribution for a false-zero winding with $Q_{s}=9, m=3$ and $L_{y}=2$. Using the connection matrix $\left[M_{w}\right]$, the first phase of this winding can be represented by:

$$
\left[M_{w}^{1, u}\right]=\frac{1}{2}\left[\begin{array}{lllllllll}
1 & -1 & 0 & 0 & -1 & 0 & 1 & 0 & 0
\end{array}\right]
$$

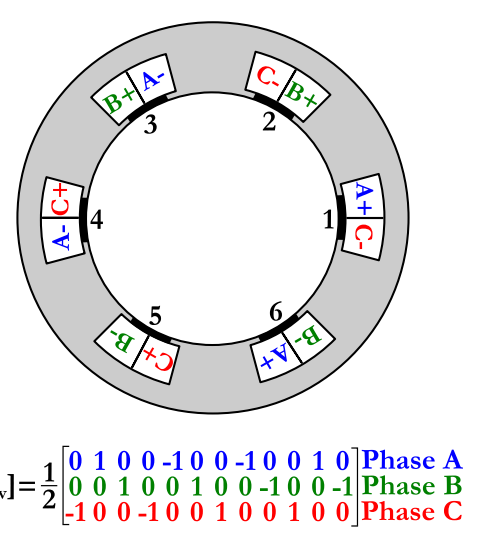

Figure 1. Two-layer winding $\left(Q_{s}=6, m=3\right.$ and $\left.L_{y}=2\right)$ and its connection matrix. 


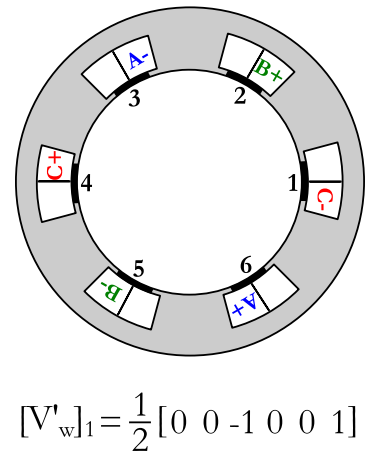

(a)

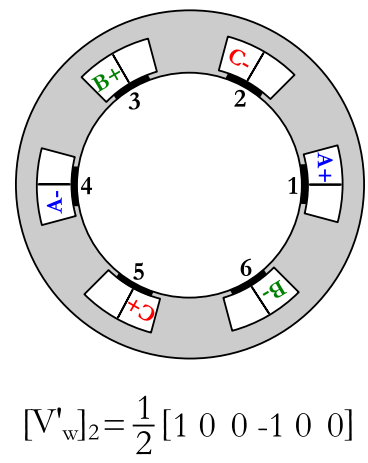

(b)

Figure 2. Two-layer winding $\left(Q_{s}=6, m=3\right.$ and $L_{y}=2$ ): (a) First sub-vector extracted, and (b) Second sub-vector extracted.

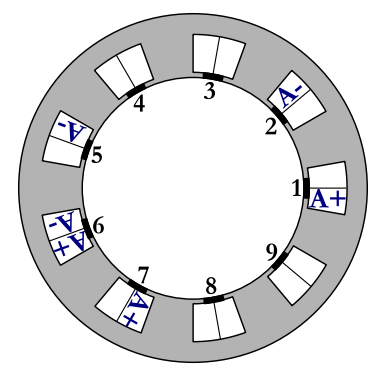

FiguRE 3. Example of a one phase distribution for a false-zero winding with $Q_{s}=9, m=3$ and $L_{y}=2$.

The sixth column (i.e., the sixth slot) is filled with a zero, this indicates the absence of the first phase in this slot. Indeed, the sixth slot is filled by the first phase in the opposite direction (2-layer winding) as given by:

$$
\left[V_{w}\right]=\frac{1}{2}\left[\begin{array}{cccccccc}
1 & 0 & 0 & -1 & 0 & 0 & 0 & \ldots \\
\ldots & 0 & -1 & 0 & -\mathbf{1} & \mathbf{1} & 0 & \ldots \\
\ldots & 1 & 0 & 0 & 0 & 0 & &
\end{array}\right]
$$

This case is called false-zero. Noting that a single layer winding can not have a false-zero (the slot is fully occupied by the phase). By introducing this new concept, multi-layer windings having false-zero will be subdivided into two categories: i) $\alpha$-windings (i.e., odd false-zero windings), and ii) $\beta$-windings (i.e., even false-zero windings). The windings having no false-zero are categorized in $\gamma$-windings.

\subsection{2. $\alpha$-WINDINGS (I.E., ODD FALSE-ZERO WINDINGS)}

A false-zero winding is odd, if forward $(+1)$ and return $(-1)$ conductor numbers are unequal, viz.,

$$
\sum_{u}\left[V_{w}^{\prime}\right]_{1}(u) \neq 0
$$

By applying (4) on the vector (8) representing the winding in Figure 3 the following vector is obtained:

$$
\left[V_{w}^{\prime}\right]_{1}=\frac{1}{2}\left[\begin{array}{lllllllll}
1 & 0 & 0 & 0 & -1 & -1 & 0 & 0 & 0
\end{array}\right]
$$

The sum of $\left[V_{w}^{\prime}\right]_{1}$ elements is nonzero, and thus this winding is an $\alpha$-winding (i.e., odd false-zero winding).

\subsection{3. $\beta$-WINDINGS (I.E., EVEN FALSE-ZERO WINDINGS)}

A false-zero winding is even, if forward $(+1)$ and return $(-1)$ conductor numbers are equal, viz.,

$$
\sum_{u}\left[V_{w}^{\prime}\right]_{1}(u)=0
$$

The winding given in Figure 4 is represented by:

$$
\left[V_{w}\right]=\frac{1}{2}\left[\begin{array}{cccccccc}
\mathbf{1} & -\mathbf{1} & 0 & -1 & 0 & 0 & 0 & \cdots \\
\cdots & 0 & 0 & 0 & -1 & 0 & -\mathbf{1} & \cdots \\
\cdots & \mathbf{1} & 0 & 1 & 0 & 0 & 0 & \cdots \\
\cdots & 0 & 0 & 0 & 1 & 0 & &
\end{array}\right]
$$

By applying (4) to (12), the sub-vector is obtained:

$$
\left[V_{w}^{\prime}\right]_{1}=\frac{1}{2}\left[\begin{array}{ccccccc}
1 & 0 & 0 & 0 & 0 & -1 & \ldots \\
\ldots & -1 & 0 & 0 & 0 & 0 & 1
\end{array}\right]
$$

The sum of $\left[V_{w}^{\prime}\right]_{1}$ elements is zero and thus this winding is a $\beta$-winding (i.e., even false-zero winding).

\section{Winding Factor Calculation}

From the usual calculation of the winding factor based on the ditribution and pitch factors 2 and formulas given in 20, an adaptation on $\left[V_{w}\right]$ is made. A generalized equation was obtained regardless of the number of slots, phases and layers. For the sake of clarity of the winding factor solution for each case,

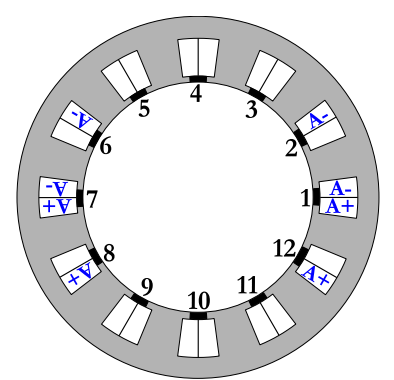

Figure 4. An example of a one phase distribution for a $\beta$-winding with $Q_{s}=12, m=3$ and $L_{y}=2$. 
the following notations are adopted throughout the paper

$$
\begin{gathered}
n=u \otimes[O]_{1, L_{y}} \\
s=1, \ldots, Q_{s} \cdot L_{y}
\end{gathered}
$$

where $\otimes$ represents the Kronecker product, and $[O]_{1, L_{y}}$ the ones matrix of dimensions $1 \times L_{y}$.

The flowchart of the method is presented in Figure 5, showing steps of the calculation and the used equations. First, the vector $\left[V_{w}\right]$ of the phase spatial distribution is tested if it is a false-zero winding. Then, the studied winding is categorized and the adequate equation is applied.

\section{1. $\gamma$-WINDINGS}

\subsubsection{DESCRIPTION}

For all single layer windings and multi-layer windings with no false-zero, the winding factor is given by:

$$
\xi_{w_{h}}^{\gamma}=\frac{m}{Q_{s}} \times\left|\sum_{s}\left[V_{w}\right](s) \times e^{-\mathrm{j} \frac{2 \pi}{Q_{s}} \times n(s) \times h}\right|
$$

where $j=\sqrt{-1}$, and $h$ is the spatial harmonic orders.

$$
\text { 3.1.2. ApplicAtion : } Q_{s}=20, m=5 \text { AND } L_{y}=2
$$

- Step 1: The distribution of the first phase of an $\gamma$-winding is given in Figure 6 (a) and represented by:

$$
\left[V_{w}\right]=\frac{1}{2}\left[\begin{array}{cccccccc}
0 & 1 & -1 & -1 & 1 & 0 & 0 & \cdots \\
\cdots & 0 & 0 & 0 & 0 & 0 & 0 & \cdots \\
\cdots & 0 & 0 & 0 & 0 & 0 & 0 & \cdots \\
\cdots & 0 & 0 & -1 & 1 & 1 & -1 & \cdots \\
\cdots & 0 & 0 & 0 & 0 & 0 & 0 & \cdots \\
\cdots & 0 & 0 & 0 & 0 & 0 & 0 & \cdots \\
\cdots & 0 & 0 & 0 & & & &
\end{array}\right]
$$

- Step 2: According to 16, the calculation of the winding factor $\xi_{w_{h}}^{\gamma}$ is given in Figure 6(b).

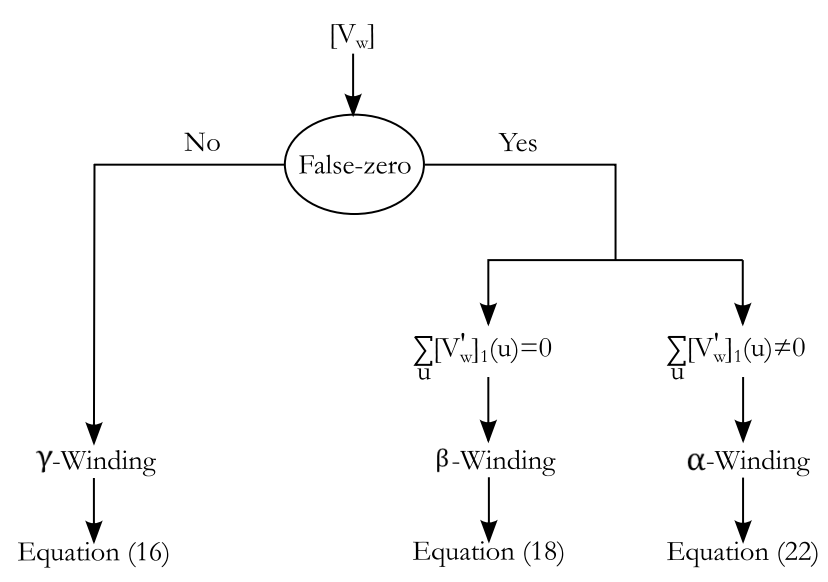

$\left[\mathrm{V}_{\mathrm{w}}\right]$ : Phase distribution in slots. $\left[\mathrm{V}_{\mathrm{w}}^{\mathrm{u}}\right]_{1}$ : Sub-vector.

Figure 5. Flowchart of the methodology.

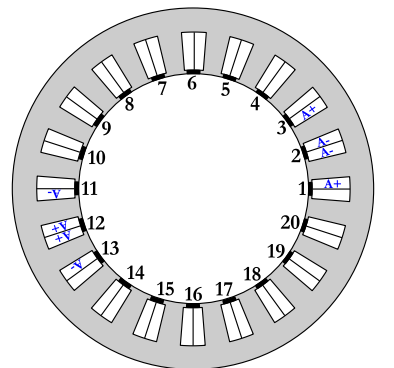

(a)

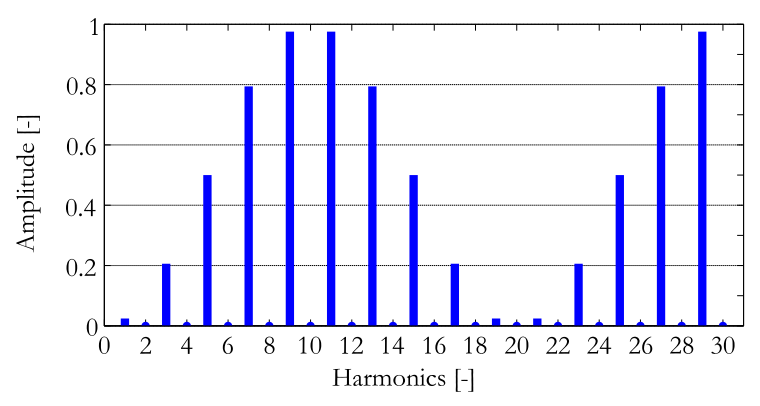

(b)

Figure 6. $\gamma$-winding with $Q_{s}=20, m=5$ and $L_{y}=2$ : (a) First phase distribution, and (b) Winding factor $\xi_{w_{h}}^{\gamma}$.

\section{2. $\beta$-Windings (i.E., Even False-Zero WINDINGS)}

\subsubsection{DESCRIPTION}

The winding factor for this category is given by:

$$
\xi_{w_{h}}^{\beta}=L_{y} \times \xi_{w_{h}}^{\gamma}
$$

3.2.2. Application: $Q_{s}=12, m=3$ AND $L_{y}=2$

- Step 1: The distribution of the first phase of a $\beta$-winding is given in Figure 7/(a) and represented by:

$$
\left[V_{w}\right]=\frac{1}{2}\left[\begin{array}{ccccccc}
\mathbf{1} & -\mathbf{1} & 0 & -1 & 0 & 0 & \ldots \\
\cdots & 0 & 0 & 0 & 0 & -1 & \ldots \\
\ldots & 0 & -\mathbf{1} & \mathbf{1} & 0 & 1 & \ldots \\
\cdots & 0 & 0 & 0 & 0 & 0 & \ldots \\
\cdots & 0 & 1 & 0 & & &
\end{array}\right]
$$

- Step 2: The sub-vector extracted is:

$$
\left[V_{w}^{\prime}\right]_{1}=\frac{1}{2}\left[\begin{array}{ccccccc}
1 & 0 & 0 & 0 & 0 & -1 & \ldots \\
\ldots & -1 & 0 & 0 & 0 & 0 & 1
\end{array}\right]
$$

- Step 3: The forward $(+1)$ and return $(-1)$ conductor numbers are equal, viz.,

$$
\sum_{u}\left[V_{w}^{\prime}\right]_{1}(u)=0
$$

- Step 4: According to 18, the calculation of the winding factor $\xi_{w_{h}}^{\beta}$ is given in Figure 7 (b). 


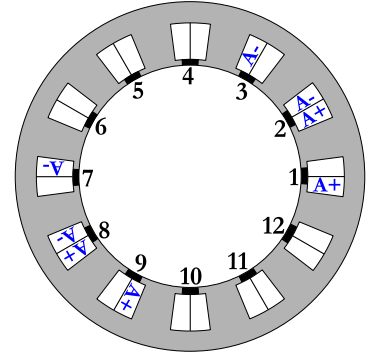

(a)

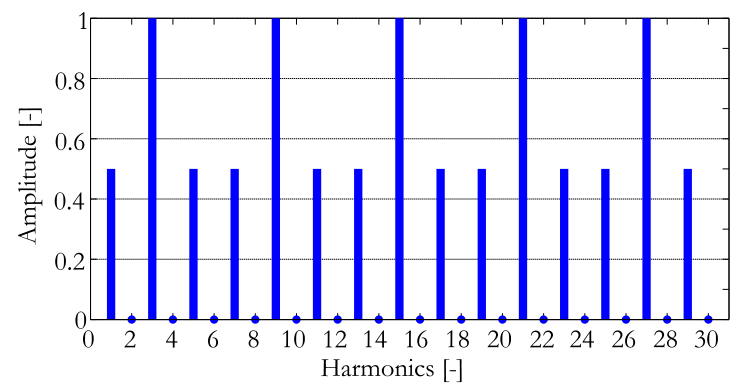

(b)

Figure 7. $\beta$-winding with $Q_{s}=12, m=3$ and $L_{y}=2$ : (a) First phase distribution, and (b) Winding factor $\xi_{w_{h}}^{\beta}$.

\section{3. $\alpha$-Windings (i.e., OdD FAlse-Zero Windings)}

\subsubsection{DESCRIPTION}

The winding factor for this category is given by:

$$
\xi_{w_{h}}^{\alpha}=c \times \xi_{w_{h}}^{\beta}
$$

where $c=Q_{s} / \lambda$ with $\lambda$ a correction coefficient defined by:

$$
\lambda= \begin{cases}t_{z+1}, & \text { for } t_{z}<Q_{s}<t_{z+1} \\ t_{z}, & \text { for } t_{z}=Q_{s}\end{cases}
$$

in which

$$
t= \begin{cases}3, & \text { for } z=1 \\ 6, & \text { for } z=2 \\ 12 \cdot(z-2), & \text { for } z>2\end{cases}
$$

with $z \in \mathbb{N}^{*}$.

3.3.2. Application : $Q_{s}=15, m=3$ AND $L_{y}=2$

- Step 1: The spatial distribution of the first phase of an $\alpha$-winding is given in Figure 8 (a) and represented by:

$$
\left[V_{w}\right]=\frac{1}{2}\left[\begin{array}{ccccccccc}
1 & 0 & 0 & -1 & 0 & 0 & 0 & 0 & \ldots \\
\cdots & -1 & 0 & 0 & 1 & 0 & 0 & 1 & \cdots \\
\cdots & 0 & \mathbf{1} & -\mathbf{1} & 0 & -1 & 0 & 0 & \ldots \\
\cdots & -1 & 0 & 0 & 1 & 0 & 0 & 0 & 0
\end{array}\right]
$$

- Step 2: The sub-vector extracted is:

$$
\left[V_{w}^{\prime}\right]_{1}=\frac{1}{2}\left[\begin{array}{ccccccccc}
1 & 0 & 0 & 0 & -1 & 0 & 0 & 1 & \ldots \\
\ldots & 1 & 0 & 0 & -1 & 0 & 0 & 0 &
\end{array}\right]
$$

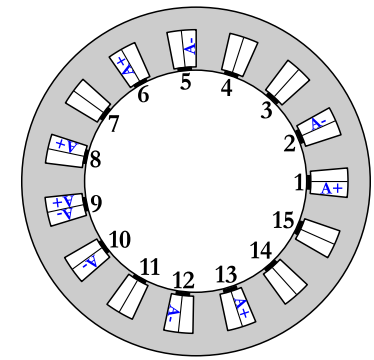

(a)

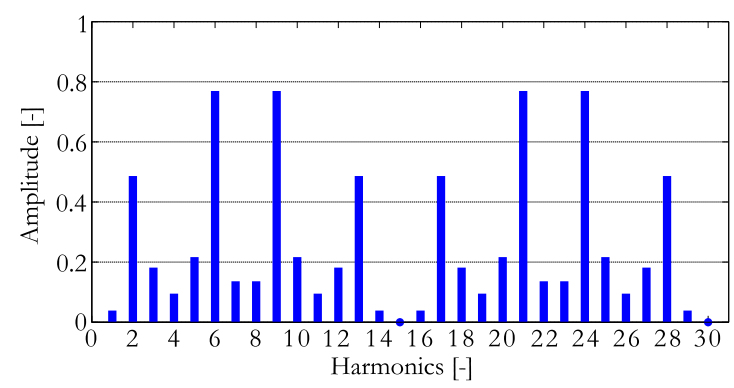

(b)

FiguRE 8. $\alpha$-winding with $Q_{s}=15, m=3$ and $L_{y}=2$ : (a) First phase distribution, and (b) Winding factor $\xi_{w_{h}}^{\alpha}$.

- Step 3: The forward $(+1)$ and return $(-1)$ conductor numbers are unequal, viz.,

$$
\sum_{u}\left[V_{w}^{\prime}\right]_{1}(u) \neq 0
$$

- Step 4: The coefficient $\lambda=24$ which gives $c=$ 0.625 .

- Step 5: The calculation of the winding factor $\xi_{w_{h}}^{\alpha}$ is given by Figure 8.(b).

\section{Multi-Layer Windings}

In order to validate the method described in this paper for the winding factor calculation with $L_{y}>2$, specific wingings, in the literature, has been used and compared with the results obtained by the developed method.

\subsection{Windings EXTRACTED IN QI et al. 15}

The authors of this paper (Qi et al.) presented a new multi-layer winding design method based on the winding function. The multi-layer winding is obtained by a superposition of several double-layer windings. The example given in [15] is an 18-slots/16-poles fractionalslot concentrated-windings permanent-magnet machine. Three multi-layer winding designs are obtained using the proposed method. The winding arrangements are shown in Figure 9 viz., i) a double layer, ii) two four-layer windings (i.e., Type1 and Type2), and ii) a six-layer winding. 


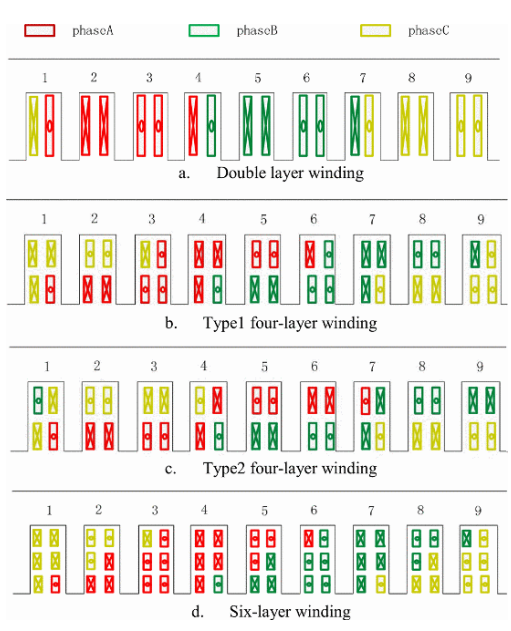

Figure 9. Different type multi-layer windings (for $Q_{s}=9$ and $\left.m=3\right)$ [15].

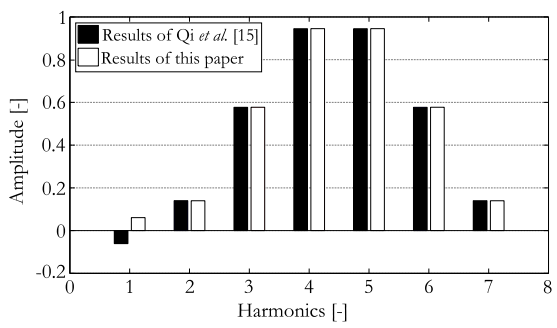

(a) Double layer winding

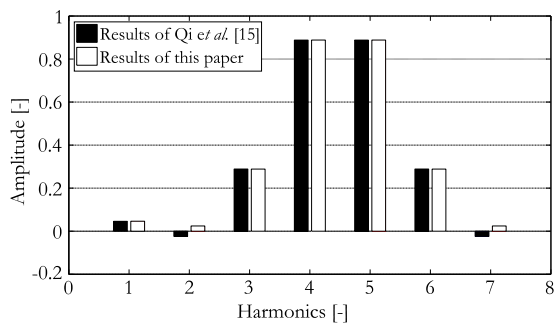

(b) Type1 four-layer winding

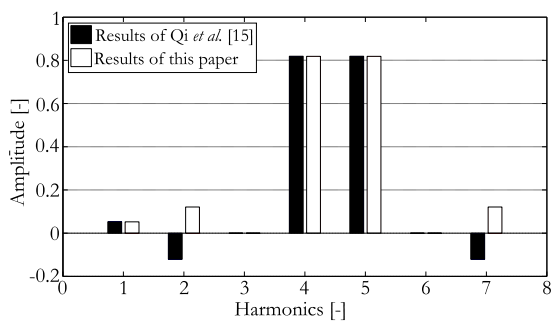

(c) Type2 four-layer winding

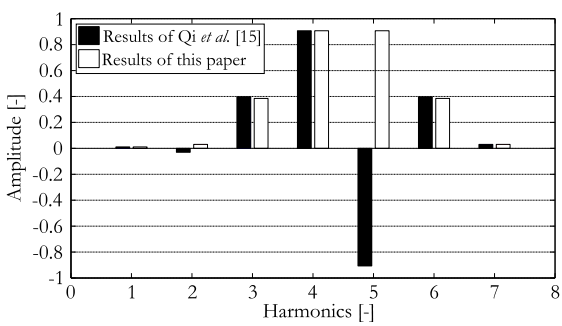

(d) Six-layer winding

Figure 10. Winding factor calculated by Qi et al. [15] and method of this paper.
The winding factor is calculated for each winding and the results are compared with those calculated by Qi et al. [15] as shown in Figure 10. Except for some harmonics for which the negative direction is taken, the amplitude is the same between the compared results for each winding.

\subsection{Windings extracted in Alberti et al. [16]}

A general theory of fractional-slot multi-layer windings has been presented by Alberti et al. [16. By applying the Star of slots method, two 9-slots/8-poles four-layer windings (see Figures 11.(b) and 11.(c)) are obtained from a 9-slots/8-poles two-layer winding (see Figure 11.(a)).

In [16, the winding factor for four-layer windings is computed starting from the one of the two-layer winding with a shift angle and based on the Star of slots method.

Compared results of the calculation are reported in Figure 12, where the same amplitude of the winding factor is obtained for each harmonic in both methods of the calculation.

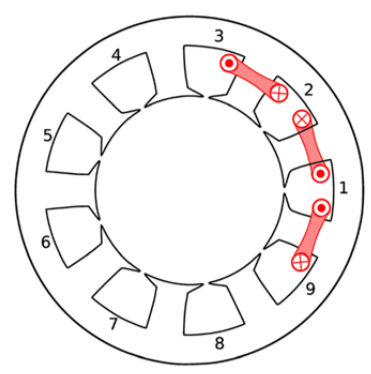

(a) 2-layer

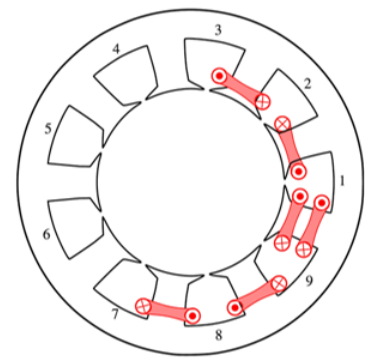

(b) 4-layer $i$

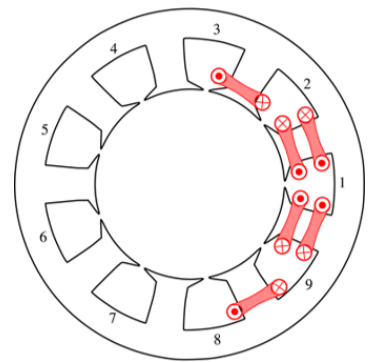

(c) 4-layer $i i$

Figure 11. Winding layout of phase A (for $Q_{s}=9$ and $m=3$ ) [16]. 


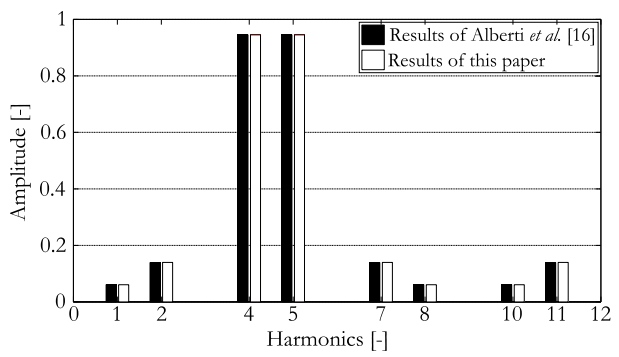

(a) 2-layer

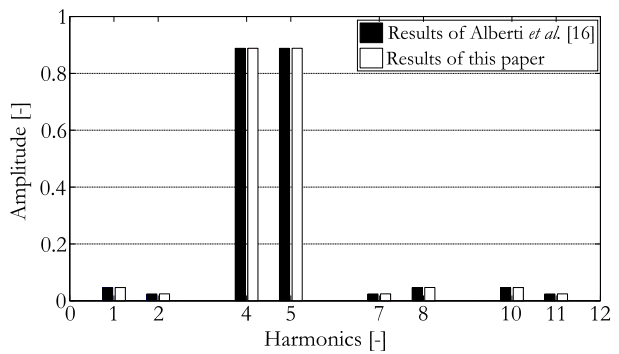

(b) 4-layer $i$

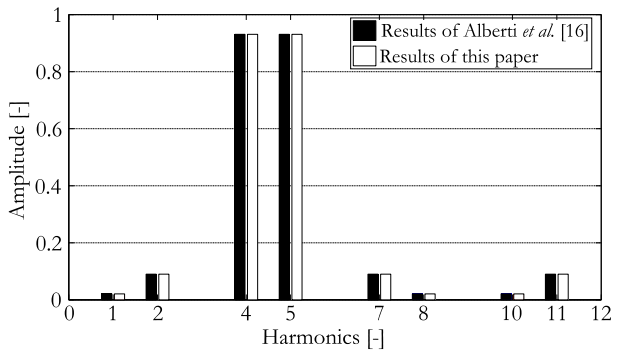

(c) 4-layer $i i$

FiguRE 12. Winding factor calculated by Alberti et al. [16] and method of this paper.

\subsection{Windings extracted in Cistelecan et al. [17]}

In [17], the winding diagram for a 12-slots/10-poles single layer layout is presented in Figure 13 (a). The double layer presented in Figure 13. (b) may be obtained from the single layer winding by doubling the first with a half number of turns per coil and shifting by 5 geometrical slots, as explained in [17]. By dou-

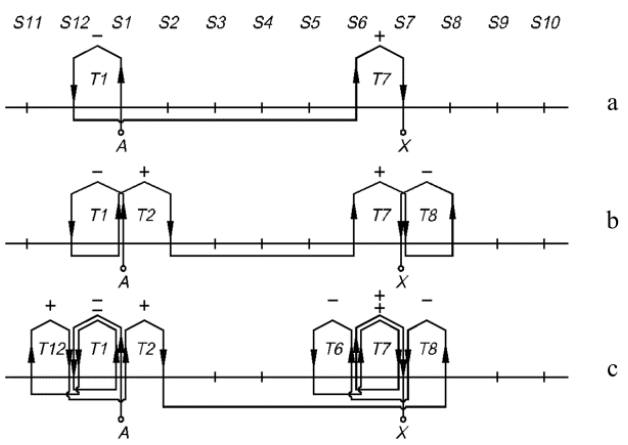

FigURE 13. Winding diagrams for 12-slots/10-poles (only one phase is represented) [17: (a) Single layer, (b) Double layer, and (c) Four-layer winding.

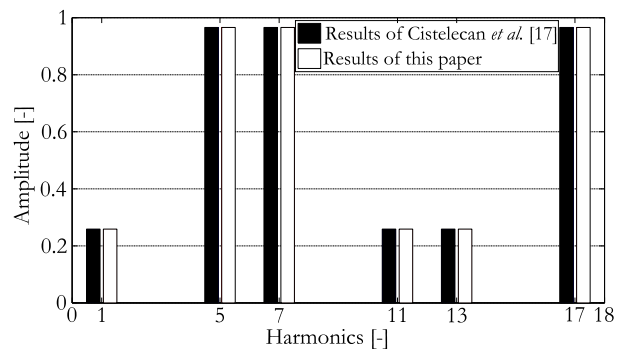

(a) Single layer winding

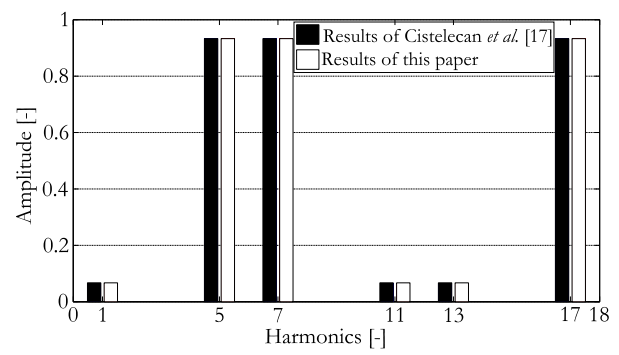

(b) Double layer winding

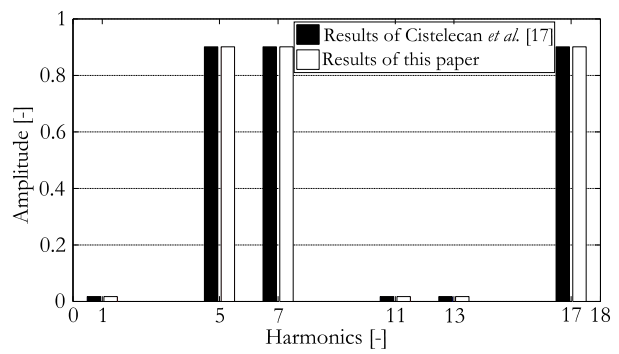

(c) Four-layer winding

FIGURE 14. Winding factor calculated by Cistelecan et al. 17. and by the method of this paper.

bling again the double-layer winding and shifting by another 5 geometrical slots, a four-layer winding may be obtained as shown in Figure 13 (c).

The winding factor has been calculated using an analytical method based on Star of slots and compared with the calculation made in this paper, results are identical. A comparison of winding factors obtained from both methods is presented in Figure 14

A special 12-slots/10-poles three layer winding is presented in [17] and shown in Figure 15

This winding has an unequal number of turns. In the developed method, the number of turns is supposed to be equal. The small difference in the results of the calculation of the winding factor, as given in Figure 16 is due to the unequal number of turns not taken into consideration in this paper.

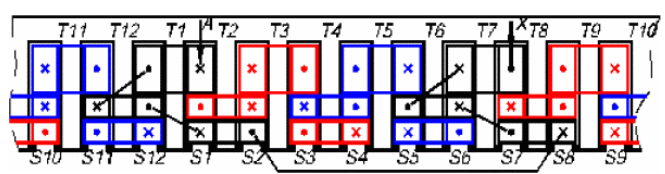

FIgURE 15. Winding diagrams for 12-slots/10-poles : Special three layer 17 . 


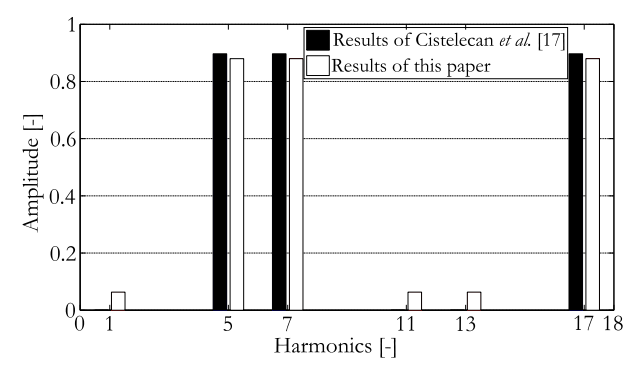

FiguRE 16. Winding factor calculated for the special three layer by Cistelecan et al. [17] and by the method of this paper.

\section{Conclusion}

A general and simple method for the calculation of the winding factor of electrical machines has been presented. This calculation is based on the matrix representation of a winding. Knowing the distribution of phases as well as the number of slots/phases/layers, the winding factor's calculation is possible for all types of balanced windings with equal turns. The method has been tested on the multi-phase windings (the three phase included) and for any number of layers. Unlike the methods existing in literature, the number of pole pairs is not necessary, which allows the seperation of the rotor and stator design. The results of the comparisons are satisfying.

This paper gives a useful tool for users to estimate the performance of a winding, focusing only on the stator parameters (i.e., number of slots, phases and layers), without the constraints on the number of pole pairs at the rotor.

Since this method is limited to windings of an equal number of turns, future work will include expanding its potential to allow the computation of windings with an unequal number of turns. The hybrid windings having unequal number of layers (e.g., winding with three-four layers) may also be considered in future studies.

\section{APPENDIX}

clear all, close all, clc,

\section{Winding's Parameters}

titreFig='Winding' 's parameters';

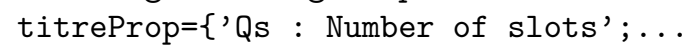

'm : Number of phases';...

'Ly : Number of layers';...

' $\mathrm{Vw}$ : Vector of distribution of phase A'\};

num_lines=1;

val_init=\{' ; ' '; ', ' ' $\}$;

dataCell=inputdlg (titreProp, titreFig, ...

num_lines, val_init, 'on');

Qs $=$ str2double (dataCell $\{1\})$;

$\mathrm{m}=$ str2double (dataCell $\{2\})$;

$\mathrm{Ly}=\mathrm{str} 2 \mathrm{double}$ (dataCell $\{3\})$;

$\mathrm{Vw}=\operatorname{str} 2 \mathrm{num}$ (dataCell $\{4\})$;

\section{Begin of Calculation}

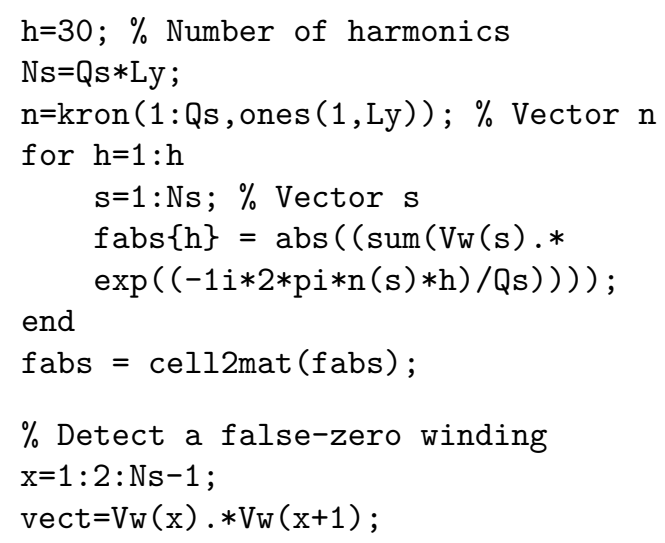

$\%$ Detect if an Alpha-/Beta-Winding $\mathrm{VW}_{-} \mathrm{p}=\mathrm{VW}_{\mathrm{w}}(\mathrm{x}) ; \operatorname{sum}=\operatorname{sum}\left(\mathrm{VW}_{-} \mathrm{p}\right)$;

\section{$\%$ Alpha-Winding}

if $($ Ly $>1) \& \&(\min ($ vect $)<0) \& \& \quad($ sum $=0)$

$\%$ Calculation of coefficient lambda $t 1=\left[\begin{array}{ll}3 & 6\end{array}\right] ; t 2=12: 12: 240 ; t=[t 1$ t2 $]$;

for $z=1: \operatorname{size}(t, 2)$;

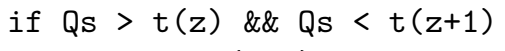

\section{$\%$ Beta-Winding}

elseif $($ Ly $>1) \& \&(\min ($ vect $)<0) \& \& \quad($ sum==0)

$\%$ Winding factor of Beta-Winding

$\mathrm{f}_{\mathrm{w}}=((\mathrm{m} * \mathrm{Ly}) / \mathrm{Qs}) * \mathrm{fabs}$;

else \% Gamma-Winding

$\%$ Winding factor of Gamma-Winding $\mathrm{fw}=(\mathrm{m} / \mathrm{Qs}) * \mathrm{fabs}$;

end

$i d x=\left(f_{w}<1 e-10\right) ; f_{w}(i d x)=0.0000 ;$

\section{Post-Processing}

Create figure with bars

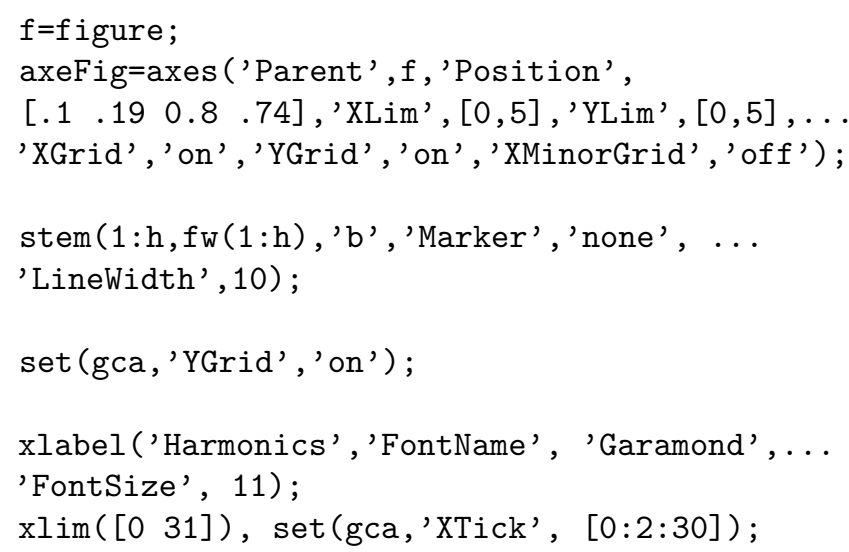




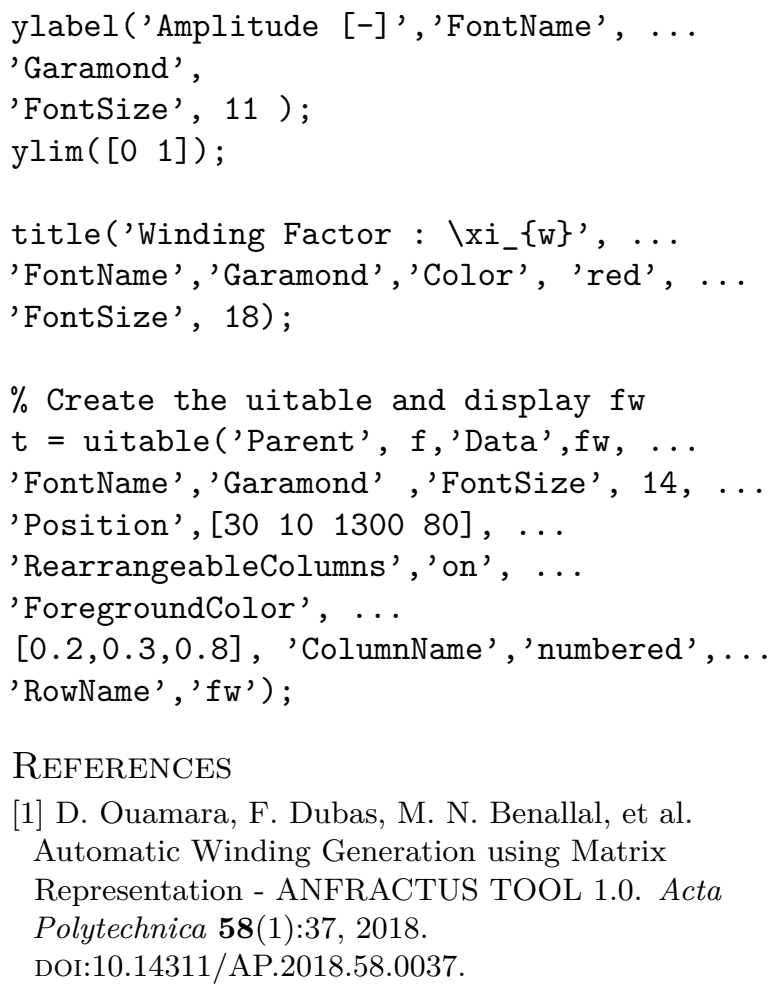

\section{REFERENCES}

[1] D. Ouamara, F. Dubas, M. N. Benallal, et al. Automatic Winding Generation using Matrix Representation - ANFRACTUS TOOL 1.0. Acta Polytechnica 58(1):37, 2018. DOI:10.14311/AP.2018.58.0037.

[2] J. L. Kirtley. Class Notes 5. Massachussets Institute of Technology, Department of Electrical Engineering and Computer Science pp. 1-9, 1997.

[3] J. Pyrhonen, T. Jokinen, V. Hrabovcova. Design of Rotating Electrical Machines, Secon Edition. Wiley \& Sons, Ltd, 2nd edn., 2014.

[4] F. Magnussen, C. Sadarangani. Winding factors and Joule losses of permanent magnet machines with concentrated windings. In IEEE International Electric Machines and Drives Conference, 2003. IEMDC'03., vol. 1, pp. 333-339. IEEE, 2003. DOI:10.1109/IEMDC.2003.1211284

[5] M. M. Liwschitz. Distribution Factors and Pitch Factors of the Harmonics of a Fractional-Slot Winding. Transactions of the American Institute of Electrical Engineers 62(10):664-666, 1943. DOI:10.1109/T-AIEE.1943.5058623

[6] N. Bianchi, S. Bolognani, M. Pre, G. Grezzani. Design considerations for fractional-slot winding configurations of synchronous machines. IEEE Transactions on Industry Applications 42(4):997-1006, 2006. DOI:10.1109/TIA.2006.876070

[7] S. E. Skaar, Ø. Krøvel, R. Nilssen. Distribution, Coil-span and Winding Factors for PM Machines with Concentrated Windings. In ICEM-2006, Chania (Greece). 2006.

[8] G. Ugalde, J. Poza, M. A. Rodriguez, A. Gonzalez. Space harmonic modeling of fractional permanent magnet machines from star of slots. In 2008 18th International Conference on Electrical Machines, pp. 16. IEEE, 2008. DOI:10.1109/ICELMACH.2008.4799937.

[9] X. Shangguan, J. Zhang, W. Zhang. Calculation on the Winding Factor and Armature Reaction MMF of a PMSM with 5-phase Fractional-slot Winding. Journal of Computers 8(3):725-732, 2013.

DOI:10.4304/jcp.8.3.725-732
[10] H.-J. Kim, D.-J. Kim, J.-P. Hong. Characteristic Analysis for Concentrated Multiple-Layer Winding Machine With Optimum Turn Ratio. IEEE Transactions on Magnetics 50(2):789-792, 2014. DOI:10.1109/TMAG.2013.2279100.

[11] A. Mohammadpour, A. Gandhi, L. Parsa. Winding factor calculation for analysis of back EMF waveform in air-core permanent magnet linear synchronous motors. IET Electric Power Applications 6(5):253, 2012. DOI:10.1049/iet-epa.2011.0292

[12] J. Cros, P. Viarouge. Synthesis of high performance PM motors with concentrated windings. In IEEE International Electric Machines and Drives Conference. IEMDC'99. Proceedings (Cat. No.99EX272), vol. 17, pp. 725-727. IEEE, 1999. DOI:10.1109/IEMDC.1999.769226

[13] Y. Yokoi, T. Higuchi, Y. Miyamoto. General formulation of winding factor for fractional-slot concentrated winding design. IET Electric Power Applications 10(4):231-239, 2016. DOI:10.1049/iet-epa.2015.0092

[14] D. Ouamara, F. Dubas, S. A. Randi, et al. Electromagnetic Comparison of 3- , 5- and 7-phases Permanent-Magnet Synchronous Machines : Mild Hybrid Traction Application. Mediterranean Journal of Modeling ES Simulation 6(1):012-022, 2016.

[15] L. Qi, T. Fan, X. Wen, et al. A novel multi-layer winding design method for Fractional-Slot Concentrated-Windings Permanent Magnet Machine. 2014 IEEE Conference and Expo Transportation Electrification Asia-Pacific (ITEC Asia-Pacific) (2):1-5, 2014. DOI:10.1109/ITEC-AP.2014.6940615

[16] L. Alberti, N. Bianchi. Theory and Design of Fractional-Slot Multilayer Windings. IEEE Transactions on Industry Applications 49(2):841-849, 2013. DOI:10.1109/TIA.2013.2242031

[17] M. Cistelecan, F. J. T. E. Ferreira, M. Popescu. Three phase tooth-concentrated multiple-layer fractional windings with low space harmonic content. In 2010 IEEE Energy Conversion Congress and Exposition, pp. 1399 1405. IEEE, 2010. DOI:10.1109/ECCE.2010.5618267

[18] P. Wach. Algorithmic method of design and analysis of fractional-slot windings of AC machines. Electrical Engineering 81(3):163-170, 1998. DOI:10.1007/BF01236235.

[19] M. V. Cistelecan, B. Cosan, M. D. Popescu. Analysis and Design Criteria for Fractional Unbalanced Windings of Three-phase Motors. In in Proc. 6th Int. Symp. Adv. Electromech. Motion Syst. (ELECTROMOTION), pp. 1-5. 2005.

[20] F. Scuiller, E. Semail, J.-F. Charpentier. General modeling of the windings for multi-phase ac machines. The European Physical Journal Applied Physics 50(3):31102, 2010. DOI:10.1051/epjap/2010058 